\title{
MICROLEAKAGE OF CLASS II COMPOSITE RESTORATIONS WITH DIFFERENT RESTORATIVE TECHNIQUES (AN IN VITRO STUDY)
}

Dalia M Tayel ${ }^{1} B D S$, Mahmoud M El-Sharkawy ${ }^{2} M S c, P h D$, El-Sayed M Mahmoud ${ }^{2} M S c, P h D$

\begin{abstract}
INTRODUCTION: Microleakage has been regarded as a primary concern for the use of composites in class II cavity restorations. Many techniques have attempted to minimize this leakage.

OBJECTIVES: The purpose of this in-vitro study was to evaluate the microleakage in class II cavities restored with composite resins applied with either incremental, bulk fill or Sonic fill techniques.

MATERIALS AND METHODS: Forty sound human permanent lower molars extracted for periodontal problems. Occluso-mesial class II cavity was prepared in each tooth, with the cervical margin of the proximal box located $1 \mathrm{~mm}$ occlusal to the cemento-enamel junction (CEJ). The prepared teeth were randomly distributed to four groups with 10 specimens each $(n=10)$. In each group, a self-etch adhesive was applied, followed by composite resin that was applied in either incremental, bulk fill or sonic fill technique; Group I: [Optibond all in one +Herculite XRV Ultra], Group II: [ Optibond all in one+ Premise flowable + Herculite XRV Ultra], Group III: [Single bond universal+Filtek bulkfill + Filtek Z250XT], Group IV: [ Optibond all in oneSonicFill]. All restored specimens were soaked in basic fuchsin dye for 24 hours, and sectioned mesiodistally to detect the extent of dye penetration by stereomicroscope. Data were collected and statistically analyzed.

RESULTS: The cervical margins showed more microleakage than the occlusal margins. Sonicfill in Group IV recorded the lowest mean value of microleakage scores among the four groups occlusally (mean=0.10), whereas Premise Flowable + Hercuilte XRV Ultra in Group II showed the highest mean value (1.20). Sonic fill in Group $1 \mathrm{~V}$ recorded the lowest mean value of microleakage scores among the four groups cervically (mean= 0.80 ), whereas Premise Flowable + Hercuilte XRV Ultra in Group II showed the highest mean value (1.60). Kruskall-Wallis test proved no significant difference among groups. Mann Whitney test proved significant difference between Group II and Group IV occlusally.

CONCLUSIONS: Sonic fill showed the best results in terms of marginal seal.
\end{abstract}

KEYWORDS: Microleakage, class II, composite.

1- Bachelor of Dentistry, Faculty of Dentistry, Misr university for science and Technology, 6 October, Egypt.

2- Professor of Conservative Dentistry, Faculty of Dentistry, Alexandria University, Alexandria, Egypt.

\section{INTRODUCTION}

Since, their initial introduction in the 1960 s, composite resins have undergone improvement in all areas, including aesthetics, wear,and handling properties. However, highpolymerization shrinkage continues to represent their major disadvantage (1). Previous research has shown polymerization shrinkage to lead to bond failure and micro-leakage of resin composite restorations (2). Microleakage is a matter of concern because it leads to staining at the margins of restorations, recurrent caries, hypersensitivity, and pulpal inflammation (3). In order to minimize stresses from polymerization shrinkage, an incremental technique is needed, $(4,5)$ in which the composite is layered and light-cured in increments of less than $2 \mathrm{~mm}$. The incremental layering of the composite reduces the $\mathrm{C}$-factor, which is defined as the ratio of the bonded surface area to the unbonded surface area of the restoration. This reduces the shrinkage stress at the toothcomposite interface by permitting the stress-relieving flow of composite from the unbounded surface towards the bonded surface (6). The use of a liner to act as a flexible intermediate layer between the restoration and the dental substrate has also been suggested as a method of relieving the stresses associated with polymerization shrinkage (7). Flowable composites have been recommended as liners due to their low viscosity, increased elasticity, and wettability, thus improving the marginal adaptation of composite restorations.

Since the layering technique and the thin $2 \mathrm{~mm}$ increments of the composites are widely recommended to minimize shrinkage stress and ensure adequate depth of cure (8-10). Therefore large posterior composite restorations would be time consuming and can imply the risk of incorporating air bubbles or contaminants between the increments. Incremental technique has not been without complications, as the material still had a predisposition to shrinkage, resulting in microleakage (11). Thus, there is a growing trend among practitioners to use bulk-fill resin based composite materials because of their more simplified procedures(12). Manufacturers mentioned that the main advancement of bulkfill composite materials, was the increased depth of cure, which probably results from higher translucency (13), and low polymerization shrinkage stress which was related to modifications in the filler content and/or organic matrix (14) with the help of advanced technology.

A novel resin composite system, SonicFill ${ }^{\mathrm{TM}}$ System (Kerr/Kavo), has been recently introduced in the market. It is indicated by the manufacturer to be used as a bulk fill posterior composite restoration, where it can be bulk filled in layers up to $5 \mathrm{~mm}$ in depth due to their reduced polymerization shrinkage, as claimed by the manufacturer. SonicFill $^{\mathrm{TM}}$ incorporates a highly-filled proprietary resin with special modifiers that react to sonic energy. As sonic 
energy is applied through a specially designed hand piece, the modifier causes the viscosity to drop (up to 87\%), increasing the flowability of the composite and enabling quick placement and precise adaptation to the cavity walls. When the sonic energy is stopped, the composite returns to a more viscous, non-slumping state that is suitable for carving and contouring (15).

A thorough understanding of the mechanism that can cause shrinkage stress and the techniques that reduce its effect, will allow the clinician to gain better use of resin composite (16). Therefore, different techniques that are used in reducing polymerization stresses were tested in the current study to evaluate their effects on the microleakage level at the cavity margins of class II composite restorations. The null hypothesis of this study was that there is no difference in the microleakage level obtained by any of the different composite application techniques used in the study.

\section{MATERIALS AND METHODS}

Forty freshly extracted sound human permanent molars free of caries, cracks, restorations and dental anomalies were collected from the out-patient clinic of the Oral Surgery Department, Faculty of Dentistry, Alexandria University. Teeth were extracted due to periodontal problem based on periodontist opinion. . The teeth were stored in $0.5 \%$ Chloramine $\mathrm{T}$ aqueous solution at $4^{\circ} \mathrm{C}$ for preventing bacterial growth (17).

The composites employed in the present study were two bulk fill composite resins: Sonicfill (Kerr, West Collins, Orange, CA, USA) (Figure 1) and Filtek bulk fill ( ${ }^{3 \mathrm{MESPE}}$ ), in addition to two conventional composites: Filtek Z250 XT ( $\left.{ }^{3 \mathrm{M}} \mathrm{ESPE}\right)$ and Herculite XRV Ultra (Kerr). Moreover, a flowable composite resin was used; Permise flowable (Kerr). Furthermore, two single-step self-etch adhesives were used: Optibond all-in-one (kerr) and Single bond universal ( $3 \mathrm{M} \mathrm{ESPE}$ ).

Occlusomesial cavity was prepared in each tooth. The cervical margin of the cavity was located $1 \mathrm{~mm}$ occlusal to the cemento-enamel junction. Cavity was prepared using parallel sides, flat end with round edges diamond stone (komet, Lemgo, Germany) of size $0.10 \mathrm{~mm}$ and length $4 \mathrm{~mm}$.It is placed in high speed hand piece under profuse water cooling. The stone was replaced by a new one after four cavity preparations. The occlusal box had buccolingual width of $3 \mathrm{~mm}$ and pulpal floor depth of $2.5 \mathrm{~mm}$ measured from the central pit. The proximal box had buccolingual width of $3 \mathrm{~mm}$ and gingival floor width of $1.5 \mathrm{~mm}$ from enamel. The cavity margins were prepared to be butt joint. The depth was standardized using a Teflon stopper placed along the shank of each stone. A periodontal probe was used to measure the width and depth of the cavities to ensure uniformity among preparations.

The teeth were randomly divided into four groups with ten teeth per group $(n=10)$ according to the restorative technique used as follows:-

- Group I: Optibond all-in-one followed by Herculite XRV Ultra applied in oblique incremental technique.

- Group II: Optibond all-in-one followed by Premise Flowable composite as a liner, then Herculite XRV Ultra was applied in oblique incremental technique.

- Group III: Single bond universal followed by Filtek bulk fill flowable, applied as a single increment starting at the deepest portion of the proximal box to a level $2 \mathrm{~mm}$ below the occlusal enamel margin and Filtek Z250 XT composite was used as a capping layer.

- Group IV: Optibond all-in-one followed by Sonic fill applied in bulk fill technique.

The teeth were mounted in manikin model with artificial teeth that served as adjacent teeth. A Tofflemire matrix retainer and metal band were placed on each molar tooth and tightly held by wooden wedge. With each cavity preparation, bonding agents and composite resin materials were applied and cured according to their manufacturers' instructions as shown in table (1). Light curing was done by light emitting diode (LED) curing unit (Elipar S10; 3M ESPE, St. Paul, MN, USA) with light intensity of 1200 $\mathrm{mW} / \mathrm{cm}^{2}$, curing time was according to manufacturer (Table 1).

For all groups, after removal of the matrix band, the composite restoration was light cured from their buccal and lingual aspects then, finished and polished with enhance one step finishing and polishing system.

The specimens were stored in an incubator set at $37^{\circ} \mathrm{C}$ for $24 \mathrm{~h}$ (18), and then subjected to thermocycling between $5^{\circ} \mathrm{C}$ to $55^{\circ} \mathrm{C}$ with 30 seconds dwell time to simulate different changes in temperature in the oral cavity (19). After thermocycling, teeth were washed and dried with oil free compressed air. Apices of teeth were sealed with sticky wax, and teeth were coated with two layers of nail polish except for an area about $1 \mathrm{~mm}$ around the margins of the restorations. Then the teeth were soaked in $1 \%$ solution of basic fuchsin dye for 24 hours, and then were rinsed in tap water. To measure the extent of microleakage, teeth were sectioned longitudinally through the center of the restorations in a mesiodistal direction with a low speed diamond saw (Isomet 4000 microsaw, Buehler, USA.). The extent of dye penetration at occlusal and cervical walls was detected by stereomicroscope (Nikon - Japan) at 25 magnification.

The degree of leakage which has occurred at the occlusal and cervical walls at the tooth/restorations interface was determined by the extent of dye penetration and was given a score from $0-4$ in an ascending pattern as follows:

A- The scoring criteria for dye penetration on the occlusal wall:

0 - No dye penetration.

1- Dye penetration into half of the enamel.

2- Dye penetration into more than half of the enamel.

3- Dye penetration into the dentin without extending into the pulpal wall.

4- Dye penetration into the pulpal wall.

B- The scoring criteria for dye penetration on the cervical wall:

0 - No dye penetration.

1- Dye penetration into half of the enamel.

2- Dye penetration into more than half of the enamel.

3- Dye penetration into the dentin without extending into the axial wall.

4- Dye penetration into the axial wall.

All data were collected and statistically analyzed by Statistical Package for Social Science version 20.0 (SPSS Inc., Chicago IL). Statistical significance was judged at the $5 \%$ level. Qualitative data of microleakage scores were described using mean, median, number, and percent. Data were analyzed using Kruskall-Wallis test, followed by Mann Whitney test for pair wise comparison between groups. 
Table 1: Composition, manufacturers and application procedures of studied materials.

\begin{tabular}{|c|c|c|c|}
\hline Product & Manufacturer & Composition & Application procedures \\
\hline $\begin{array}{l}\text { Herculite XRV Ultra } \\
\text { (nanohybrid } \\
\text { light cured } \\
\text { composite) }\end{array}$ & Kerr Orange, CA, USA & $\begin{array}{c}\text { Resin: Uncured Methacrylate Ester Monomeras } \\
\text { Filler: prepolymerized fillers (PPF), Silica } \\
\text { nanofillers }(20-50 \mathrm{~nm}) \text {, and Barium glass }(0.4 \\
\text { micron) } \\
\text { Filler content by wt\%: } \mathbf{7 8 \%}\end{array}$ & $\begin{array}{c}\text { Apply an increment of } 2 \mathrm{~mm} \text { thickness } \\
\text { and light cure for } 20 \mathrm{~s}\end{array}$ \\
\hline $\begin{array}{l}\text { Sonicfill } \\
\text { (sonically } \\
\text { activated light- } \\
\text { cured bulkfill } \\
\text { composite) }\end{array}$ & $\begin{array}{l}\text { Kerr Orange, } \\
\text { CA, USA }\end{array}$ & $\begin{array}{l}\text { Resin: Bis-EMA, TEGDMA, BISGMA. } \\
\text { Filler: } \mathrm{SiO} 2 \text {, Glass, oxide, chemicals. } \\
\text { Filler content by wt } \%: 83.5 \%\end{array}$ & $\begin{array}{l}\text { Screw the provided tips onto the } \\
\text { handpiece head. Adjust the intensity } \\
\text { of the sonic energy on the shank. } \\
\text { Deliver the sonic energy by the foot } \\
\text { control. Inject composite in bulk } \\
\text { increment of 5mm thickness. Release } \\
\text { the foot control to cease the sonic } \\
\text { energy. Carve the composite resin. } \\
\text { Light cure for } 20 \text { seconds. }\end{array}$ \\
\hline $\begin{array}{l}\text { Filtek Z250XT } \\
\text { (nanohybrid } \\
\text { light-cured } \\
\text { universal } \\
\text { composite) }\end{array}$ & 3M ESPE & $\begin{array}{c}\text { Resin: BIS-GMA, UDMA, BIS-EMA, PEGDMA, } \\
\text { TEGDMA, } \\
\text { Fillers: surface-modified zirconia/silica particles } \\
\text { with average size of } 3 \text { micron or less. Non- } \\
\text { agglomerated/non-aggregated } 20 \mathrm{~nm} \text { surface- } \\
\text { modified silica particles. } \\
\text { Filler content by wt } \%: 82 \% .\end{array}$ & $\begin{array}{l}\text { rement of } 2 \mathrm{~mm} \text { thickness } \\
\text { ght cure for } 20 \mathrm{~s} \text {. }\end{array}$ \\
\hline $\begin{array}{l}\text { Filtek Bulkfill } \\
\text { (light-cured } \\
\text { flowable } \\
\text { composite) }\end{array}$ & 3M ESPE & 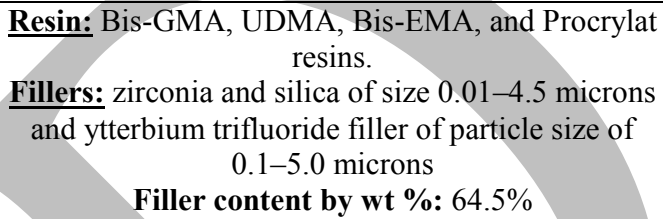 & $\begin{array}{l}\text { Apply an increment up to } 4 \mathrm{~mm} \\
\text { thickness and light cure for } \mathbf{2 0 s}\end{array}$ \\
\hline $\begin{array}{c}\text { Premise } \\
\text { Flowable (light-cured } \\
\text { flowable } \\
\text { composite) }\end{array}$ & $\begin{array}{l}\text { Kerr Orange, CA, } \\
\text { USA }\end{array}$ & $\begin{array}{c}\text { Resin: BIS-EMA, TEGDMA, } \\
\frac{\text { Fillers: }}{\text { Prepolymerized fillers, Barium glass, Silica }} \\
\text { filler, initiator, stabilizers and Organophosphate } \\
\text { dispersant } \\
\text { Filler content by wt } \mathbf{0}: 72.5 \%\end{array}$ & $\begin{array}{c}\text { Apply an increment of } 2 \mathrm{~mm} \text { thickness } \\
\text { and light cure for } 20 \mathrm{~s}\end{array}$ \\
\hline $\begin{array}{l}\text { Optibond } \\
\text { All-In-One } \\
\text { (light-cured } \\
\text { one-bottle self- } \\
\text { etch adhesive) }\end{array}$ & $\begin{array}{r}\text { Kerr Oran } \\
\text { US }\end{array}$ & $\begin{array}{c}\text { Resin: GPDM, mono- and di-functional } \\
\text { methacrylate co-monomers, water, acetone, } \\
\text { ethanol, } \\
\text { Fillers: CQ photo-initiator, nano-silica sodium } \\
\text { hexafluorosilicate. } \\
\text { Filler content by wt } \%: 7 \%\end{array}$ & $\begin{array}{c}\text { Apply two coats with scrubbing } \\
\text { motion for } 20 \mathrm{~s} \text { each, then air dry with } \\
\text { medium force for } 5 \mathrm{~s} \text {, then light cure } \\
\text { for } 10 \mathrm{~s} .\end{array}$ \\
\hline $\begin{array}{l}\text { Single bond } \\
\text { Universal } \\
\text { (light-cured } \\
\text { one-bottle self- } \\
\text { etch adhesive) }\end{array}$ & $3 \mathrm{M} \mathrm{E}$ & $\begin{array}{l}\text { MDP phosphate monomer } \\
\text { HEMA. Dimethacrylate resin. } \\
\text { Silane. Vitre bond copolymer. } \\
\text { Filler. Ethanol. Water. Initiator }\end{array}$ & $\begin{array}{l}\text { Apply adhesive with a brush in a } \\
\text { scrubbing motion for } 20 \text { s, then air dry } \\
\text { gently for } 5 \mathrm{~s} \text { and light cure for } 10 \mathrm{~s} \text {. }\end{array}$ \\
\hline $\begin{array}{c}\text { Enhance } \\
\text { (one step } \\
\text { finishing } \\
\text { and polishing system). }\end{array}$ & $\begin{array}{l}\text { Dentsply De Trey; } \\
\text { Kontsanz, } \\
\text { Germany }\end{array}$ & $\begin{array}{l}\text { Aluminum oxide- silicone dioxide finishing wheel- } \\
\text { impregnated UDMA }(40 \mu \mathrm{m})\end{array}$ & \\
\hline
\end{tabular}

\section{RESULTS}

The stereomicroscopic images for the sectioned specimens were illustrated at occlusal wall and cervical wall in (Fig. 1, $2,3,4)$.

The mean values for dye penetration through the composite-tooth interface at the occlusal walls are shown in table (2) and presented graphically in (Fig. 5). It was shown that the Sonicfill in Group IV recorded the lowest mean value of microleakage scores among the four groups (mean $=0.10)$, whereas Premise flowable + Hercuilte Ultra in Group II showed the highest mean value (1.20). KruskallWallis test proved that there was no statistically significant difference among the four groups. Mann Whitney test proved significant difference between the mean values of Group II versus Group IV. 
Table 2: Comparison between the different groups according to microleakage scores at the occlusal walls

\begin{tabular}{|c|c|c|c|c|c|c|c|c|}
\hline \multirow{2}{*}{ Microleakage scores } & \multicolumn{2}{|c|}{$\begin{array}{l}\text { Group I } \\
(\mathrm{n}=10)\end{array}$} & \multicolumn{2}{|c|}{$\begin{array}{c}\text { Group II } \\
(\mathbf{n}=10)\end{array}$} & \multicolumn{2}{|c|}{$\begin{array}{c}\text { Group III } \\
(\mathbf{n}=10)\end{array}$} & \multicolumn{2}{|c|}{$\begin{array}{c}\text { Group IV } \\
(\mathbf{n}=10)\end{array}$} \\
\hline & No. & $\%$ & No. & $\%$ & No. & $\%$ & No. & $\%$ \\
\hline \multicolumn{9}{|l|}{ Scoring for occlusal wall } \\
\hline 0 : No dye penetration & 8 & 80.0 & 5 & 50.0 & 7 & 70.0 & 9 & 90.0 \\
\hline 1: Dye penetration into half of the enamel & 2 & 20.0 & 1 & 10.0 & 2 & 20.0 & 1 & 10.0 \\
\hline 2: Dye penetration into more than half of the enamel & 0 & 0.0 & 2 & 20.0 & 1 & 10.0 & 0 & 0.0 \\
\hline 3: Dye penetration into the dentin without extending into the pulpal wall & 0 & 0.0 & 1 & 10.0 & 0 & 0.0 & 0 & 0.0 \\
\hline 4: Dye penetration into the pulpal wall & 0 & 0.0 & 1 & 10.0 & 0 & 0.0 & 0 & 0.0 \\
\hline Min. - Max. & \multirow{3}{*}{\multicolumn{2}{|c|}{$\begin{array}{c}0.0-1.0 \\
0.20 \pm 0.42\end{array}$}} & \multirow{3}{*}{\multicolumn{2}{|c|}{$\begin{array}{c}0.0-4.0 \\
1.20 \pm 1.48 \\
0.50\end{array}$}} & \multirow{2}{*}{\multicolumn{2}{|c|}{$\begin{array}{c}0.0-2.0 \\
0.40 \pm 0.70\end{array}$}} & \multicolumn{2}{|c|}{$0.0-1.0$} \\
\hline Mean \pm SD. & & & & & & & \multicolumn{2}{|c|}{$0.10 \pm 0.32$} \\
\hline Median & & & & & \multicolumn{2}{|c|}{0.0} & \multicolumn{2}{|c|}{0.0} \\
\hline $\mathrm{KW}(\mathrm{p})$ & \multicolumn{8}{|c|}{$5.814(0.121)$} \\
\hline $\mathrm{p}_{1}$ & & & \multicolumn{2}{|c|}{0.091} & & & \multicolumn{2}{|c|}{0.542} \\
\hline $\mathrm{p}_{2}$ & & & & & \multicolumn{2}{|c|}{0.214} & \multicolumn{2}{|c|}{$0.040^{*}$} \\
\hline $\mathrm{P}_{3}$ & & & & & \multicolumn{4}{|c|}{0.255} \\
\hline
\end{tabular}

KW: Kruskal Wallis test, pairwise comparison was done using Mann Whitney test $\mathrm{p}_{1}: \mathrm{p}$ value for comparing between group I and each other group $\mathrm{p}_{2}$ : $\mathrm{p}$ value for comparing between group II with group III and group IV $\mathrm{p}_{3}$ : $\mathrm{p}$ value for comparing between group III and group IV

Regarding dye penetration through the composite-tooth interface at the gingival walls, results are shown in table (3) and presented graphically in (Fig. 6). It was shown that Sonicfill in Group 1V recorded the lowest mean value of microleakage scores among the four groups (mean $=0.80$ ), whereas Premise Flowable + Hercuilte Ultra in Group II showed the highest mean value (1.60). Kruskall-Wallis test proved that there was no statistically significant difference among the four groups.

Mann Whitney test has shown statistical significant difference between the mean values of microleakage scores at the occlusal margins versus the gingival margins in each of the four studied groups, where it was shown that in all the groups, the mean value was significantly higher gingivally than occlusally. In Group I (Herculite XRV Ultra applied incrementally), $\mathrm{p}=0.023$. In Group II (Premise Flowable liner/Herculite XRV Ultra applied incrementally), $p=0.046$, in Group III (Filtek Bulk fill applied in bulk/Filek Z 250 capping layer) $\mathrm{p}=0.011$, and in Group IV (Sonic Fill applied in bulk) $p=0.038$


Figure 2: Sectioned specimen with microleakage score 2 (dye penetrates into more than half of the enamel) at: Occlusal wall and (b): Gingival wall.

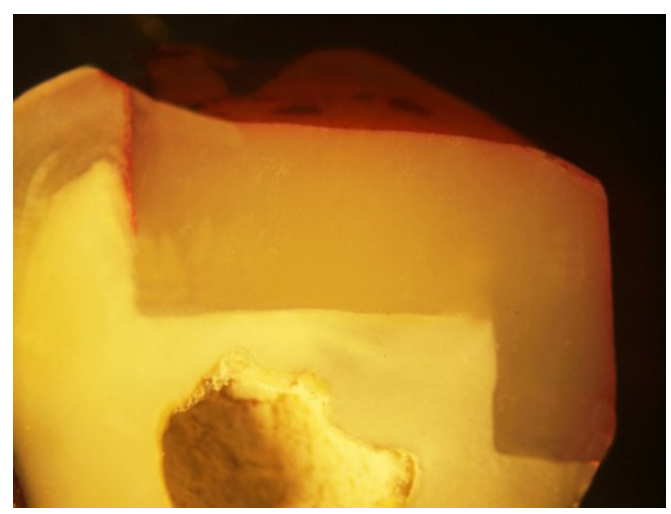

Figure 3: Sectioned specimens with microleakage score 3 (dye penetrates into the dentin) at: Occlusal wall.

Figure 1: Sectioned specimen with microleakage score 0 (no dye penetration) at: Occlusal wall and Gingival wall. 


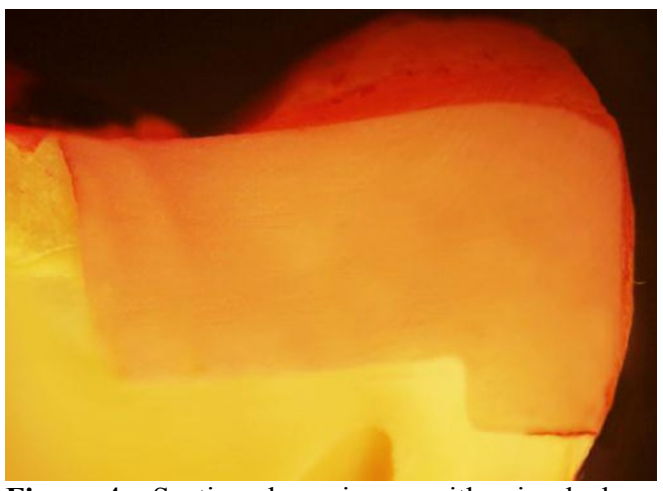

Figure 4: Sectioned specimens with microleakage score 3 (dye penetrates into the dentin) at: Gingival wall.

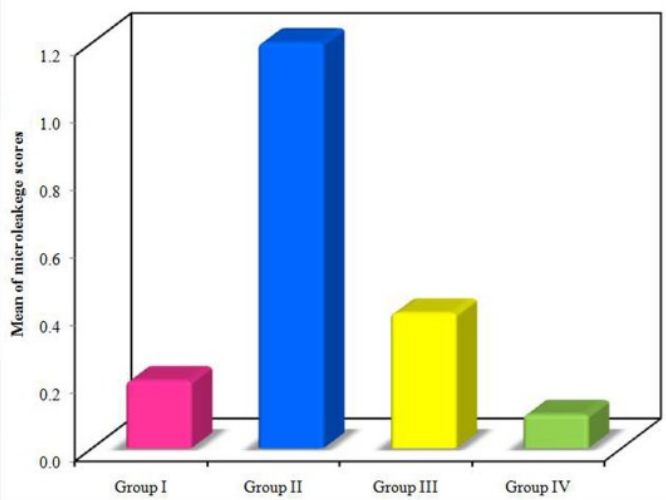

Figure 5: Comparison between the different groups according to microleakage scores at the occlusal walls.

Table 3: Comparison between the different groups according to dye penetration scores at the cervical wall.

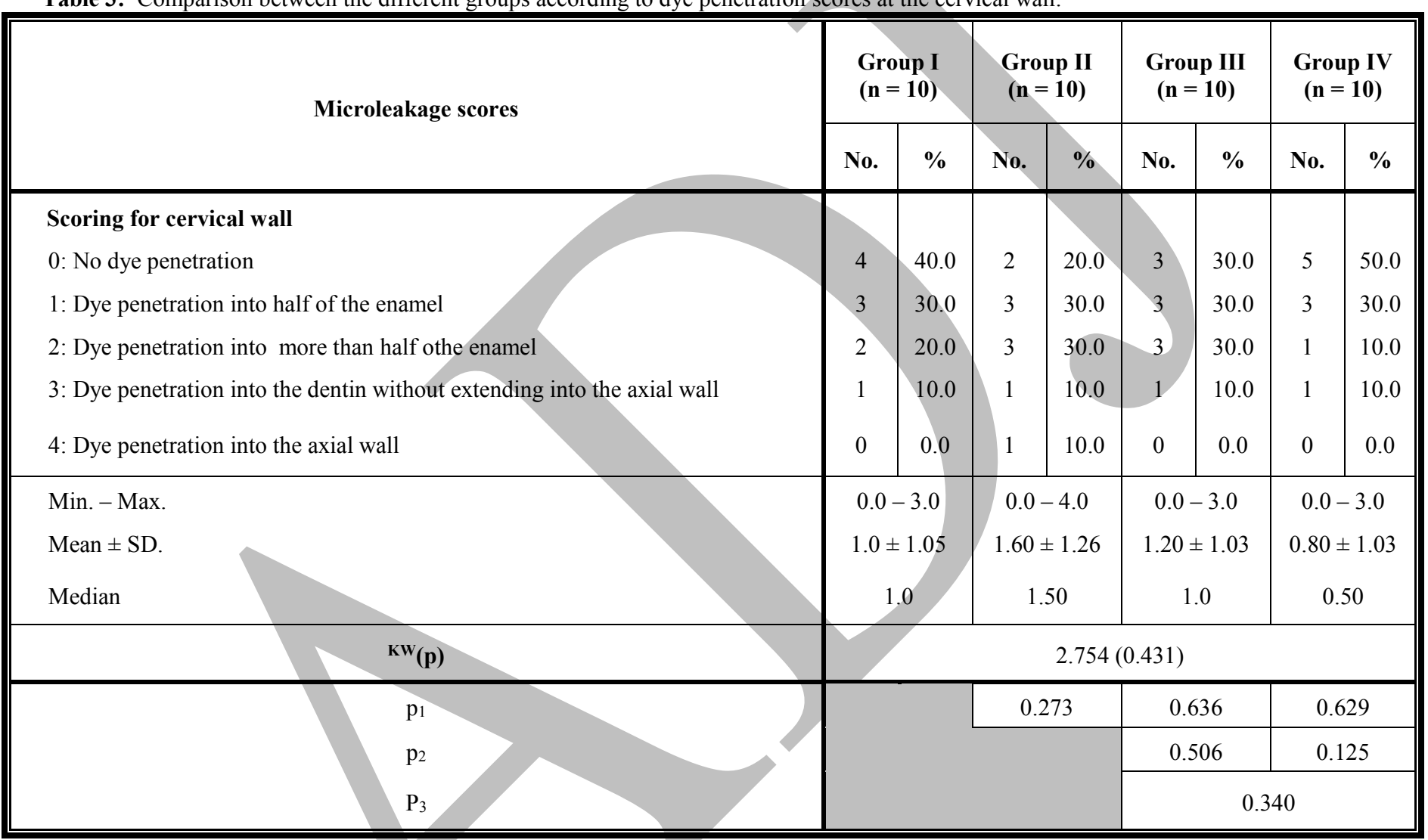

KW: Kruskal Wallis test, pairwise comparison was done using Mann Whitney test

$\mathrm{p}_{1}$ : $\mathrm{p}$ value for comparing between group I and each other group

$\mathrm{p}_{2}$ : $\mathrm{p}$ value for comparing between group II with group III and group IV

$\mathrm{p}_{3}$ : $\mathrm{p}$ value for comparing between group III and group IV

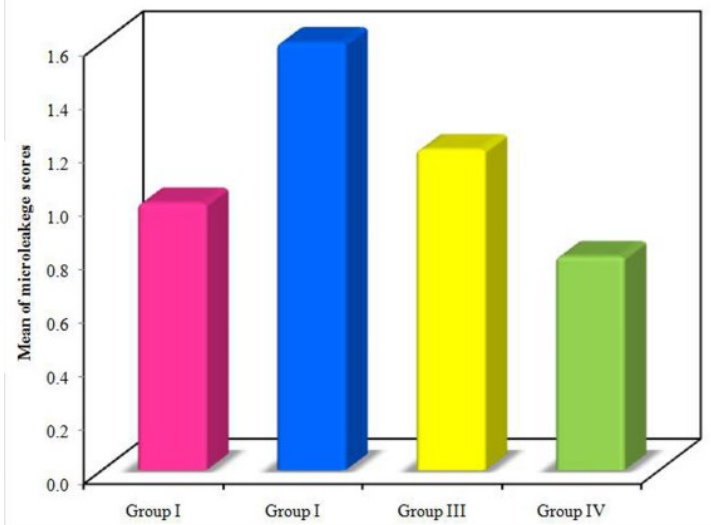

Figure 6: Comparison between the different groups according to microleakage scores at the cervical walls.

\section{DISCUSSION}

The purpose of the current microleakage test was to evaluate the sealing ability of the restoration-adhesive complex. The results of in-vitro microleakage studies are close to clinical reality, because human teeth and clinical protocols are used. Failure of the restoration to seal the tooth may contribute to marginal staining, adverse pulpal response, postoperative sensitivity and recurrent caries (20).

Class II restorations were considered to be an appropriate design for this microleakage study, as the longitudinal mesiodistal sectioning of the specimens allowed the evaluation of both occlusal and gingival leakage simultaneously (21). Thermocycling was applied in the current study as it is an in vitro process of subjecting the restoration and the tooth to temperature extremes. This 
simulates the momentary introduction of hot and cold temperatures in the oral cavity and highlights the difference in thermal expansion between the tooth and restoration, which may cause gap formation (22). There are several methods to detect microleakage (23), one of these methods is the organic dye method that was chosen for this study because of its extensive use in the literature and its ease of use. Therefore, $0.5 \%$ basic fuchsin aqueous solution was used for 24 hours at $37^{\circ} \mathrm{C}(24)$.

The null hypothesis of this study is accepted since there was no difference in the microleakage level obtained by any of the different composite restorative techniques, except with the Sonicfill, which showed significantly lower microleakage at the occlusal margins than that obtained by Premise Flowable/Herculite XRV Ultra, The latter technique obtained the highest microleakage score with the least sealing ability at the occlusal margin among the four studied groups and the sonicfill obtained the lowest microleakage scores with the highest sealing ability at the occlusal margin among the four groups, this might explain the significant difference between the sonic fill group and the Premise Flowable/Herculite XRV Ultra group occlusally.

The result of the present study showed significant increase in microleakage at the gingival margins than the occlusal margins in the four studied group. This could be explained by the thinner structure of enamel at the cervical area, which may become more susceptible to leakage. Greater thickness of the enamel occlusally allows better penetration of the adhesive system, forming stronger micromechanical bond with the composite (25). The results regarding microleakage at the gingival step were in agreement with Moazzami et al. in 2014 (26). Their explanation was that the gingival floor of the proximal box of class II cavity preparation yielded the greatest distance to light source. When the distance between the light-curing tip and the resin surface is $>2 \mathrm{~mm}$, the light intensity is significantly reduced, which may prevent adequate polymerization of resin composite materials (27). Low degree of monomer conversion might increase unconverted double bonds, making the resin more susceptible to degradation by premature breakdown at the toothrestoration interface (28), thus leading greater leakage value (27).

The current study showed that score zero was predominantly reported for both Sonicfill nanohybrid composite and Herculite XRV Ultra nanohybrid composite. This was in agreement with Poggio et al. in 2013 (29) who evaluated microleakage in Class II composite restoration using similar materials and techniques as the current study. Their results showed that score zero was also prevalent for the Sonicfill and the nanohybrid composite which was applied in oblique incremental techniques. A possible explanation might have been due to the less free linear shrinkage, and consequent stresses of the nanohybrid composite due to the lower monomer and higher filler content. In addition, Herculite XRV Ultra contains prepolymerized fillers that aid in obtaining proper handling characteristics, together with reducing the polymerization shrinkage. Composite resin could shrink less during polymerization when a portion of its volume had already been polymerized by means of the pre-polymerized particles (31).
Sonic fill and Herculite XRV Ultra were placed in class II cavity preparation with cervical margin $1 \mathrm{~mm}$ above the cemento-enamel junction. The results showed that there was no significant difference between their microleakge scores. This was in agreement with Kalmowicz et al. in 2015 (32) who evaluated microleakage in class II cavity with cervical margin $1 \mathrm{~mm}$ above cemento-enamel junction and $1 \mathrm{~mm}$ below the cemento-enamel junction, and restored the cavities with Sonicfill and Herculite XRV Ultra nanohybrid composite. No significant difference between leakage scores of the two types of composites, either above or below the cemento-enamel junction. The most important issue is that score zero (no dye penetration), was limited to preparations extending above the cemento-enamel junction. This might be explained as the material technology wasn't the only limiting factor in terms of microleakage. Instead, they suggested that the primary limiting factor was the nature of the bonded substrate, as evidenced by the decreased level of microleakage at enamel than at cementum.

As previously mentioned, there was no significant difference in the microleakage level between the sonically delivered composite resin and the incrementally placed conventional composite (Herculite XRV Ultra). This was in contrast with Kapoor et al. in 2016 (33), whose results showed that Sonic fill demonstrated significantly better results than the incrementally applied composite resin. They related their results to the increased flowability and wettability of the material gained by the activation of composite with sonic energy, which favors their adaptation to the cavity wall, and thus decreases the risk for void inclusion at the margins.

The low viscosity bulk fill (Filtek Bulk fill) flowable composite showed better sealing ability than the low viscosity conventional flowable composite (Premise Flow). This finding might be due to exclusion of the TEGDMA monomer in Filtek Bulkfill, which has low molecular weight that may result in increased shrinkage (34).

Although it was expected by Pecie R et al (35) that since the filler load of Premise Flowable composite is $72 \%$ close to that of the restorative resin composites, it should be expected to have relatively low polymerization shrinkage, the present study didn't show any improvement in the sealing ability of the Premise flowable composite at the gingival margin.

Hernsndes et al. in 2014 (36) found that the thickness of the flowable composite liner has an important role in decreasing microleakage. In their study, a liner of $2 \mathrm{~mm}$ thickness showed more microleakage than liners of $1 \mathrm{~mm}$ and $0.5 \mathrm{~mm}$ thicknesses. Their explanation was that when the first increment was light cured, a high polymerization rate occurs on the top surface of the composite resin increment and a lower polymerization rate on the bottom surface. This situation creates stress flow of polymerization shrinkage from the cervical wall to the surrounding walls (buccal and lingual), increasing stress concentration in the adhesive layer of the cervical wall, which can open gap in the cervical interface. The thin increment showed less microleakage, probably due to better polymerization of the bottom surface of the increment, thus better distribution of shrinkage stress for the surrounding and the cervical walls (37), this study was in agreement with the current study.

The results of the current study were in contrast to Malmstrom et al. in 2002 (38), who assessed the 
microleakage that occurred at the gingival margins of composite restorations extending superior to the cementoenamel junction. They found that placement of a flowable composite resin as a liner of $2 \mathrm{~mm}$ thickness on the gingival step obtained significantly less leakage when compared to flowable composite liner of $0.5 \mathrm{~mm}$ thickness. They related their findings to the low modulus of elasticity of flowable composites, which allows them to absorb polymerization stresses of the overlying restorative composites (39). Stress absorption is a function of material's thickness and modulus of elasticity. For a given elastic modulus, a thicker layer might absorb more stress and thereby decrease microleakage. Also the current study disagreed with Simi and Suprabh in 2011 (40) who found that placement of a liner beneath nano-composite restorations resulted in significant reduction in microleakage. They explained that the application of liners reduces the configuration factor ( $\mathrm{C}$-factor) of the cavity by decreasing the total bonded surfaces of the subsequently applied restorative composite.

\section{CONCLUSIONS}

Within the limitations of this study, it was concluded that none of the restorative techniques can completely eliminate microleakage either occlusally or cervically,. The sonically derived composite resin (Sonic Fill) showed slightly better marginal seal than the other restorative techniques used. The use of Bulkfill flowable composite (Filtek bulk fill) can reduce microleakage in comparison to conventional flowable composite (Premise flowable).

\section{CONFLICT OF INTEREST}

The authors declare that they have no conflict of interest.

\section{REFERENCES}

1. Alonso RC, Sinhoreti MA, Correr Sobrinho L, Consani S, Goes MF. Effect of resin liners on the microleakage of class V dental composite restorations. J Appl Oral Sci 2004; 12: 56-61.

2. Bayındır YZ, Bayındır F, Zorba YO, Turgut H. Influence of different bonding systems and soft-start polymerization marginal gap formation. Mater Res Innovat 2008; 12: 166-71.

3. Simi B, Suprabha B. Evaluation of microleakage in posterior nanocomposite restorations with adhesive liners. J Conserv Dent 2011; 14: 178-81.

4. Kwon Y, Ferracane J, Lee IB. Effect of layering methods, composite type, and flowable liner on the polymerization shrinkage stress of light cured composites. Dent Mater 2012; 28: 801-9.

5. Soares CJ, Bicalho AA, Tantbirojn D, Versluis A. Polymerization shrinkage stresses in a premolar restored with different composite resins and different incremental techniques. J Adhes Dent 2013; 15: 341-50.

6. Bicalho AA, Valdivia AD, Barreto BC, Tantbirojn D, Versluis A, Soares CJ. Incremental filling technique and composite material-Part II: Shrinkage and shrinkage stresses. Oper Dent 2014; 39: e83-e92.

7. Radhika M, Sajjan GS, Kumaraswamy BN, Mittal N. Effect of different placement techniques on marginal microleakage of deep class-II cavities restored with two composite resin formulations. J Conserv Dent 2010; 13: $9-15$.
8. Nagpal R, Manuja N, Tyagi SP, Singh UP. In vitro bonding effectiveness of self-etch adhesives with different application techniques: a microleakage and scanning electron microscopic study. J Conserv Dent 2011; 14: 258-63.

9. Cenci M, Demarco F, de Carvalho R. Class II composite resin restorations with two polymerization techniques: relationship between microtensile bond strength and marginal leakage. J Dent 2005; 33: 603-10.

10. Duarte S Jr, Saad JR. Marginal adaptation of class 2 adhesive restorations. Quintessence Int 2008; 39: 413-9.

11. Tarle Z, Attin T, Marovic D, Andermatt L, Ristic M, Tauböck TT. Influence of irradiation time on subsurface degree of conversion and microhardness of high-viscosity bulk-fill resin composites. Clin Oral Investig 2015; 19: $831-40$.

12. Ilie N, Kebler A, Duner J. Influence of various irradiation processes on the mechanical properties and polymerization kinetics of bulk-fill resin based composites. J Dent 2013; 41: 695-702.

13. Surefil SDR Flow: Compilation of Studies - Dentsply. Available

at: https:/www.dentsply.com/content/dam/dentsply/master/ document/2/2015-SureFil-SDR-flow-Literature-Reviewzvcxypk-en-1509.pdf.

14. Leprince JG, Palin WM, Vanacker J, Sabbsgh J, Devaux J, Leloup G. Physico-mechanical characteristics of commercially available bulk-fill composites. J Dent 2014; 42: $993-1000$

15. Sybron Dental Specialties Inc., "SonicFillTM System," 2011. Available at: www.sonicfill.eu.

16. Cakir D, Sergent R, Burgess JO. Polymerization Shrinkage-A Clinical Review. Inside Dentistry. 2007. Available at:

https://www.dentalaegis.com/id/2007/09/polymerizationshrinkage-clinical-review\#sthash.lPsiEd1b.dpuf

17. Vichi A, Margvelashvili M, Goracci C, Papacchini F, Ferrari M. Bonding and sealing ability of a new selfadhering flowable composite resin in class I restorations. Clin Oral Investig 2013; 17: 1497-506.

18. Tuloglu N, Tunc E, Ozer S, Bayrak S. Shear bond strength of self-adhering flowable composite on dentin with and without application of an adhesive system. J Appl Biomater Funct Mater 2014; 12: 97-101.

19. Küçükeşmen C, Sönmez H. Microleakage of class v composite restorations with different bonding systems on fluorosed teeth. Eur J Dent 2008; 2: 48-58.

20. Eick, JD, Gwinnett AJ, Pashley DH, Robinson SJ. Current concepts on adhesion to dentin. Crit Rev Oral Biol Med 1997; 83: 306-35.

21. Demarco FF, Ramos OL, Mota CS, Formolo E, Justino LM. Influence of different restorative techniques on microleakage in Class II cavities with gingival wall in cementum. Oper Dent 2001; 26: 253-9.

22. Rajbaran S, Dannheimer M, De Wet F. The effect of thermocycling on the determination of microleakage in permite amalgam restorations. SADJ 2009; 64: 394-6.

23. Gogna R, Jagadis S, Shashikal K. A comparative in vitro study of microleakage by a radioactive isotope and compressive strength of three nanofilled composite resin restorations. J Conserv Dent 2011; 14: 128-31.

24. Wahab FK, Shaini FJ, Morgano SM. The effect of thermocycling on microleakage of several commercially 
available composite Class V restorations in vitro. J Prosthet Dent 2003; 90: 168-74.

25. Fabianelli A, Goracci C, Ferrari M. Sealing ability of packable resin composites in class II restorations. J Adhes Dent 2003; 5: 217-23.

26. Moazzami SM, Sarabi N, Hajizadeh H, Majidinia S, Li Y, Meharry MR, et al. Efficacy of four lining materials in sandwich technique to reduce microleakage in class II composite resin restorations. Oper Dent 2014; 39: 256-63.

27. Poskus LT, Placido E, Cardoso PE. Influence of adhesive system and placement technique on microleakage of resinbased composite restorations. J Adhes Dent 2004; 6: 22732.

28. Coutinho M, Trevizam NC, Takayassu RN, Leme AA, Soares GP. Distance and protective barrier effects on the composite resin degree of conversion. J Contemp Clin Dent 2013; 4: 152-5.

29. Poggio C, Chiesa M, Scribante A, Mekler J, Colombo M. Microleakage in Class II composite restorations with margins below the CEJ: in vitro evaluation of different restorative techniques. Med Oral Patol Oral Cir Bucal 2013; 18: 793-8

30. Kemp-Scholte CM, Davidson CL. Complete marginal seal of Class $\mathrm{V}$ resin composite restorations effected by increased flexibility. J Dent Res 1990; 69: 1240-3.

31. Hatrick CD, Eakle WS. Dental Materials: Clinical Applications for Dental Assistants and Dental Hygienists. Canada: Elsevier Health Sciences, 2015. 384.

32. Kalmowicz J, Phebus JG, Owens BM, Johnson WW, King GT. Microleakage of Class I and II Composite Resin Restorations Using a Sonic-resin Placement System. Oper Dent 2015; 40: 653-61.

33. Kapoor N, Bahuguna N, Anand S. Influence of composite insertion technique on gap formation. J Conserv Dent 2016; 19: 77-81.

34. Kim RJ, Kim YJ, Choi NS, Lee IB. Polymerization shrinkage, modulus, and shrinkage stress related to toothrestoration interfacial debonding in bulk-fill composites. J Dent 2015; 43: 430-9.

35. Pecie R, Onisor I, Krejci I, Bortolotto T. Marginal adaptation of direct class II composite restorations with different cavity liners. Oper Dent 2013; 38: E210-20.

36. Hernandes NM, Catelan A, Soares GP, Ambrosano GM, Lima DA, Marchi GM, et al. Influence of flowable composite and restorative technique on microleakage of class II restorations. J Investig Clin Dent 2014; 5: 283-8.

37. Oliveira LC, Duarte S Jr, Araujo CA, Abrahão A. Effect of low-elastic modulus liner and base as stress-absorbing layer in composite resin restorations. Dent Mater 2010; 26: e15969.

38. Malmström HS, Schlueter M, Roach T, Moss ME. The effect of thickness of flowable resins on marginal leakage in class 2 composite restoration. Oper Dent 2002; 27: 373-80.

39. Labella R, Lambrechts P, Van Meerbeek B, Vanherle G. Polymerization shrinkage and elasticity of flowable composites and filled adhesives. Dent Mater. 1999; 15: 128-37.

40. Simi B, Suprabha BS. Evaluation of microleakage in posterior nanocomposite restoration with adhesive linner. $\mathrm{J}$ Consev Dent 2011; 14: 178-81. 